\title{
Drug scandal exposes French regulators to public ire
}

PARIS - The scandal over the diabetes drug benfluorex, which is alleged to have caused an estimated 500 to 2,000 deaths from valvular heart disease in France, is on course to trigger a major overhaul of the country's drug and health safety system.

A devastating 244-page report on the affair, published last month by the governmental General Inspectorate of Social Affairs (IGAS), accused the pharmaceutical company Servier, headquartered in the suburbs of Paris, of misleading authorities about the true nature of benfluorex, which was sold under the brand name Mediator.

Commenting on the IGAS findings, Health Minister Xavier Bertrand of France told reporters at a press conference on 15 January that Servier was the prime culprit in the debacle but conceded that there were also "serious malfunctions" in the drug regulatory system.

The next day, he said on Europe 1 radio that he and all French health ministers since 1976, when benfluorex first hit the market here, should speak at the parliamentary hearings on the issue, now getting underway. The drug, which was often prescribed as an appetite suppressant to people without diabetes, was withdrawn in France in 2009, several years after other European countries. Servier, France's second largest drug maker, never sought authorization for sale in the US.

Inspectors have questioned how benfluorex was kept on the market after studies had established it produced the same dangerous metabolite as an ingredient in the diet drug FenPhen, which was withdrawn from the market in 1997 for causing heart problems.

Although benfluorex was taken off France's market two years ago, it was not until pulmonologist Irène Frachon's book Mediator $150 \mathrm{mg}$ was published last June that the issue blew up into a scandal in France.

The subsequent campaign to uncover the facts has been led mainly by Gérard Bapt, cardiologist and chair of a parliamentary commission of inquiry into the drug, along with the independent monthly medical review journal Prescrire (Prescribe) and Philippe Even, president of the Necker Institute, a Paris-based think tank and funding institute tied to the Necker Medical School.

"There is now every reason to be optimistic that the French system will be reformed structurally, although there will be opposition from some politicians, the administration and the pharmaceutical industry," says Even. Bapt adds, "this is the biggest medical scandal France has ever known."

Bertrand promised urgent and radical measures to build a new health safety system so there would "not be a new Mediator tomorrow." On 17 January, he said on France Inter radio that a bill would be debated by Parliament before the end of the year. And in June, IGAS will present the government with a second report proposing ways to reform the pharmocovigilance system and the French

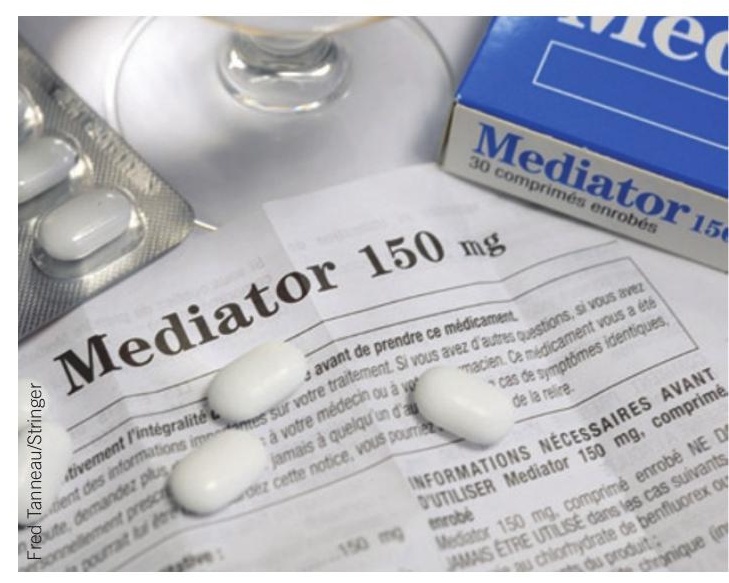

Mediation process: Drug triggers major changes.

Health Products Safety Agency (AFSSAPS).

The scandal has caused major shockwaves. AFSSAPS chief Jean Marimbert was pressured to step down last month. Bertrand, meanwhile, pledged to drastically scale back industry funding of the agency and mentioned the possibility of new rules on conflict of interest inspired by the US Sunshine Act.

Meanwhile, Jacques Servier, who heads Servier, has been ordered to appear at a regional court this month, as alleged victims of the drug have pressed charges against the company. Reacting to the IGAS report, Servier said in a statement that the findings were surprising and "did not appear to conform to reality."

Barbara Casassus

\section{New initiative aims to grow UK life sciences}

Four of the UK's leading healthcare industry associations, encompassing the pharmaceutical, biotechnology, medical device and diagnostic industries, are joining forces under a new initiative called LifeSciencesUK.

Launched at the beginning of January, LifeSciencesUK aims to help strengthen and grow the UK life science sector for the benefit of both patients and the UK economy as a whole. The four founding members are the Association of British Healthcare Industries, the Association of the British Pharmaceutical Industry, the Biolndustry Association and the British In Vitro Diagnostics Association.

The new initiative came out of the realization that the four associations were collaborating more and more on certain topics. This type of collaboration has imtensified ever since the formation of the UK's Office for Life Sciences in 2009, which provided them all with the same main point of contact within the UK government.
"The four trade associations have been working closely together over the last couple of years, and this [initiative] is really a formalization of that, providing a single unified voice on shared, key issues," says Joe Wildy, director of public affairs and policy at the Biolndustry Association.

These key issues include improving the investment environment for UK healthcare companies, improving patient access to new medicines, devices, technologies and diagnostics, and demonstrating the importance of UK life sciences to the UK economy.

The setting up of LifeSciencesUK has been broadly welcomed. "I can say that it is long overdue," says Tony Turner, innovations director at Cranfield Ventures, which manages spin-outs and licensing from Cranfield University. "The UK needs a stronger voice in life sciences, where it has particular strengths."

Jon Evans 